\title{
LA TEORÍA HABERMASIANA: DE SUS HERENCIAS FRANKFURTIANAS A LA SUPERACIÓN DEL PARADIGMA CARTESIANO
}

Habermas' theory: from its frankfurt legacy to the superation of descartes' paradigm

Andréa Maila Voss Kominek*

\section{Resumo}

El presente artículo es resultado de la condensación de algunas investigaciones desarrolladas para la construcción de la fundamentación teórica de mi tesis doctoral y tiene como objetivo presentar la problemática y la discusión de uno de los teóricos más influyentes de la actualidad: la temática habermasiana presente, especialmente, en su Teoría de la Acción Comunicativa.

El artículo propone, inicialmente, presentar la idea habermasiana de "despedida de la Filosofía”, ubicando la teoría habermasiana entre la filosofía y la sociología. Sigue presentando los orígenes y herencias frankfurtianas, remarcando la influencia de la primera generación en su obra. Superando la herencia frankfurtiana, apunta para la necesidad habermasiana de superar el paradigma cartesiano. Finalmente, presenta, de manera resumida el llamado "paradigma habermasiano" con el consecuente optimismo del "paradigma de la intersubjetividad”.

Palavras-chave: Teoria da ação comunicativa. Teoria crítica. Escola de Frankfurt. Paradigma cartesiano. Paradigma habermasiano.

* Professora de Filosofia das Faculdades do Brasil; Mestre em Tecnologia pela Universidade Tecnológica Federal do Paraná; doutora em Sociologia pela Universidade de Salamanca. Email: andreakominek@ yahoo.com.br 


\section{Abstract}

The present article is the result of the condensation of some investigations developed for the theoretical basis of my doctoral thesis and has as s objective to present the problem and a discussion of one of the most influent theorists nowadays: Habermas' discussion, presents, especially in his Theory of Communicative Action.Initially the article sets out to present the Habermas' idea of "farewell of the philosophy", locating the Habermas' theory between the philosophy and the sociology. It follows presenting the Frankfurtian origins and inheritances, emphasizing the influence of the first generation in its work. Surpassing the Frankfurtian inheritance, it points to the Habermas' necessity to overcome the Cartesian Paradigm. Finally, it presents, in a summarized way, the so called "Habermasian Paradigm", with the consequent optimism of the "Paradigm of the Inter-subjectivity":

Keywords: Communication action. Critical theory. Frankfurt school. Habermas' paradigm. Descartes' paradigm.

"Nadie es sujeto en la soledad y el asilamiento, sino que es sujeto entre sujetos: el sentido de la vida humana no es un monólogo, sino que proviene del intercambio de sentidos, de la polifonía coral".

Fernando Savater

\section{INTRODUCCIÓN}

La teoría habermasiana es, sin duda, una de las más fecundas y amplias de la actualidad, lo que permite no sólo una abrangencia temática impresionante sino también una aplicación practica considerable. Respecto al tema "tecnología y sociedad", objeto central de esta revista, puede traer importantes contribuciones, especialmente en cuestiones como la comprensión e inclusión del otro (sociedad) y su relación con las transformaciones materiales del mundo actual (tecnología). Este artículo 
busca contribuir, desde una perspectiva teórica-filosófica, para una reflexión que abra caminos hacia el avanzo de esta discusión. Así, lejos de constituir un punto final, es la invitación a que a partir de él se puedan desarrollar amplios, seguidos y necesarios debates.

De esta forma, con el objetivo de desarrollar una reflexión que sirva de fundamento e invitación a dichos debates, el artículo se organiza de la siguiente forma: 1- subraya el hecho de la teoría habermasiana haber abandonado cualquier pretensión salvífica que pudiera estar presente en la filosofía clásica tradicional y de ubicarse entre dos mundos teóricos: la filosofía y la sociología; 2- remarca los orígenes frankfurtianos de Habermas, subrayando las herencias que asume de la primera generación de dicha escuela y aquellas que busca superar; 3 - a partir de lo expuesto en los apartados iniciales, presenta la principal contribución de la teoría habermasiana: la superación del paradigma cartesiano y la proposición del paradigma habermasiano.

\section{LA DESPEDIDA DE LA FILOSOFÍA: ENTRE LA FILOSOFÍA Y LA SOCIOLOGÍA}

Para comprender la temática e intenciones habermasianas, es importante primeramente tener claro que, aunque tenga amplitudes y fundamento filosóficos, la base teórica habermasiana cuestiona la clásica postura totalizante de la Filosofía y se presenta en una actitud modesta y pósmetafísica, sin olvidar los sueños ilustrados de emancipación. Sueños de profundo carácter práctico y compromiso político, sin connotaciones utópicas, como muchos quieren hacer parecer.

Si la modernidad y la identidad moderna están en crisis, las ciencias en general y la filosofía, como consecuencia, también lo están. Una crisis vista, por algunos teóricos, como una pérdida, como un problema con nefastas consecuencias al tradicional poder de la filosofía, como apunta Gómez-Heras ${ }^{1}$

La desorientación que padecen las ciencias se acrecienta por la crisis que afecta la filosofía misma. El escepticismo respecto a la posibilidad de la metafísica, el desfondamiento de la fe en una filosofía universal, que actúe de guía del que hacer 
humano, significa un desplome de la confianza en la razón. Competencia de ésta era conferir sentido último a todo ser, valor o fin, al desempeñar la función de relacionarlos con lo expresado en los términos "verdad" o "bien". Al retirar el hombre su confianza en las diversas formas de racionalidad filosófica, se contribuyó al derrumbamiento de la fe en una razón "absoluta", a partir de la cual el mundo, la historia y la humanidad poseyeran sentido. ${ }^{2}$

La presente propuesta se delinea, sin embargo, a partir de una lectura optimista de la crisis y de una idea que puede parecer, a primera vista, una paradoja: una investigación de cuño filosófico que sugiere el desprestigio de la propia filosofía, su desvaloración y fragilidad (impotencia?) ante los gigantescos problemas actuales de la sociedad contemporánea occidental. Libre, sin embargo, de la históricamente autoimpuesta necesidad de resolver problemas, crear fórmulas eficaces y formular certezas definitivas, la filosofía descubre una nueva manera de relacionarse con la ciencia y se permite, en una actitud menos arrogante y prepotente, admitir sus límites y compensarlos con otras fuentes de conocimiento que no exclusivamente filosóficas.

Se trata de lo que Habermas, sin duda uno de los filósofos actuales de mayor influencia intelectual, de amplia proyección internacional y de producción teórica casi inabarcable, llama de "despedida de la filosofía”, que al abandonar su intención de resolver problemas, desemboca en diálogos edificantes, exonerada ya de cualquier pretensión salvífica. Dentro de este contexto, construye su teoría y su concepto de racionalidad situados en una comprensión del mundo y en un cambio de paradigma propios, sobre el cual sólo una teoría de la sociedad con intención práctica como la suya podría reflexionar y contribuir a la realización de las metas emancipatorias de la modernidad. Se desarrolla así, una teoría heredera del deseo de hacer real el sueño ilustrado de que la razón ocupe un lugar fundamental en la historia humana, aunque sea una razón con minúscula y no instrumental, sino práctico-moral y comunicativa.

Así, la obra de Habermas puede ser entendida, en el panorama filosófico actual, como una fecunda simbiosis entre la preocupación 
gnoseológica de la filosofía y la inquietud social de la sociología. Se constituye, antes de nada, en la elaboración de un diagnóstico sensible del tiempo presente, y en este diagnóstico encuentra su papel político como intelectual, fruto de la creencia de que en una praxis política consecuente y eficaz no cabe el mero activismo, una vez que ello representaría riesgos inútiles además de infértiles.

En el actual contexto de imposibilidad de cerrar los ojos para los límites de cualquier teoría aislada ante el crecimiento de las dificultades a combatir, se impone la relevancia de una filosofía como la habermasiana que, aunque admita las dificultades de tender puentes entre la teoría y la praxis, no renuncia a hacerlo. Sí renuncia a la confortable y segura protección académica de la torre de marfil que por siglos ha servido de morada de la filosofía y se lanza al "mundo real", ensucia las manos con cuestiones sociales y moja los pantalones en los pantanos económicos.

Muchos filósofos, científicos y pensadores en general sucumben al pesimismo y a la falta de esperanza ante las tensiones que rigen la escena social, política y económica en nuestro siglo. El temor a no lograr hacer lo que les gustaría termina por paralizarlos, impidiéndoles de hacer cualquier cosa. La postura habermasiana, por otro lado, se construye exactamente en el vacío entre el pesimismo paralizante y el optimismo ingenuo.

Así, la teoría de la acción comunicativa, de J. Habermas, se inserta en la visión dentro de la cual la filosofía renuncia a tener un carácter totalizante y abandona su ambición (o ingenuidad) de querer construir teorías ontológicas de la naturaleza o de construir de un sujeto genérico, como se puede percibir en esta cita:

En el lugar del sujeto solitario, que se vuelve para los objetos y que, en la reflexión, se toma a uno mismo por objeto, entra no sólo la idea de un conocimiento lingüísticamente mediatizado y relacionado con la acción pero también el nexo de la practica y de la comunicación cotidiana, en la cual están insertas las operaciones cognitivas que tienen desde el origen un carácter intersubjetivo y, al mismo tiempo, cooperativo. ${ }^{3}$

Las filosofías afluyen, actualmente, hacia un mismo punto, hacia una teoría de la racionalidad, conduciendo consecuentemente a una nueva forma de relacionarse la filosofía y la ciencia mutuamente. Hubo un 
período en la historia de la humanidad en que el ser humano consideraba su razón ilimitada, cuando había muchas certezas, como apunta el propio Habermas:

Los filósofos del siglo XVIII abrigaban todavía la esperanza de que las ciencias objetivantes, los fundamentos universalistas de la moral y del derecho y el arte autónoma no sólo se desarrollarían atendiendo rigurosamente al sentido y a la lógica específica de cada una de estas esferas, sino que los potenciales cognitivos acumulados pudieran liberarse de su forma esotérica. ${ }^{4}$

Actualmente, sin embargo, con el avance acelerado de las ciencias, se sabe que el conocimiento actual es sólo más grande que el conocimiento del pasado, pero menor que del futuro. Se encuentra avalado, por lo tanto, el estatuto de la "verdad", de las "certezas". Una "verdad" permanece como verdad sólo hasta que otra la supere o invalide. A partir de esta postura filosófica, Habermas desarrolla sus reflexiones a través de la discusión intelectual con diversos e importantes autores de la teoría social, especialmente los frankfurtianos, tomando muchas veces como punto de partida sus contribuciones teóricas. Su teoría sería, en fin, un gran intento de actualizar y lograr los objetivos del programa de la teoría crítica de los años 30 .

\section{ORÍGENES Y HERENCIAS FRANKFURTIANAS: ILUSIONES Y OBJETIVOS}

Habermas, el principal representante de la segunda generación de la Escuela de Frankfurt, es heredero de sus orígenes marxistas, su problemática y la tarea a que se propone. Así como la teoría marxista, la teoría crítica de la Escuela de Frankfurt, que es el embrión de la teoría de la acción comunicativa habermasiana, cree ser necesario despertar el hombre de su alienación para que él pueda disfrutar de todas sus posibilidades materiales y espirituales, o sea, hacer ver a los hombres que son y deben ser ellos los protagonistas de su propia vida. La teoría crítica intenta, por lo tanto, conservar la relación propuesta por Marx entre teoría y práctica, concibiendo la teoría como elemento catalizador y necesario para el deseado cambio social, pero, no obstante, proponiendo la necesidad de 
algunos cambios metodológicos, pues, como nos dice Unzueta, "para no caer en el diagnóstico pesimista de la sociedad en términos de jaula de hierro, había que repensar la cuestión de la racionalidad y situarla en un molde epistemológico diferente". ${ }^{5}$

Diferente de la teoría de la acción comunicativa, sin embargo, el contexto histórico del nacimiento de la teoría crítica frankfurtiana era todavía muy parecido a los problemas con los que se enfrentaba Marx en el desarrollo de su teoría económica-filosófica: 1- la influencia en la vida humana del desarrollo desenfrenado de las fuerzas capitalistas; 2la complejidad creciente del sistema social y consecuente necesidad de mayor control social; 3- la sustitución de la moral tradicional por una moral universal; 4- la crisis de identidad cultural, resultado de las interpretaciones totales del mundo y de la historia.

Así, la teoría crítica y la teoría marxista tienen en común dos puntos esenciales: el diagnóstico que hacen de la sociedad capitalista y de sus problemas, y la idea de la necesidad de desenmascarar los poderes opresores de dicha sociedad. Lo que irá a diferenciar a Habermas de la tradición crítica de la Escuela de Frankfurt será que, diferente de la primera generación de los frankfutianos, Habermas, como Marx, posee una visión optimista del futuro y cree en la posibilidad de llegar a construir, un día, una sociedad verdaderamente racional, pero dentro de su propia comprensión de lo que es la racionalidad. Lo que queda claro en esta cita de Mardones:

Quizá la diferencia siga estribando en que frente al pesimismo aporético de la primera generación, Habermas sale una y otra vez a recorrer los caminos de la realidad cabalgando esperanzado en el corcel de la razón y con la lanza en ristre de la crítica. Hay mucho de caballeresco en la teoría crítica. Pero des que no está insita la esperanza en la razón que busca el entendimiento por la vía de la comunicación? ${ }^{6}$

Los principales teóricos que han influenciado la base filosófica de la Escuela de Frankfurt y, por lo tanto, a Habermas, han sido Hegel, Marx y Freud, teorías sin duda demasiado complejas para que sean presentadas en este trabajo, que se limita a apuntar, a continuación, la principal contribución de cada uno de ellos para el desarrollo de la teoría crítica, con 
el objetivo de permitir comprender mejor la problemática y la discusión habermasiana.

La principal contribución de Hegel reside en su denuncia de la contradicción entre la presunta "verdad" de la situación histórica burguesa, o sea, su discurso de armonía, justicia y libertad, y la realidad. Para Hegel la organización de la sociedad burguesa constituye un reino de profundas contradicciones, encubierta engañosamente por un discurso de legalidad. La teoría crítica absorbe y fortalece dicha denuncia, pero critica y abandona lo que, bajo su perspectiva, habría sido la solución hegeliana al problema por él apuntado.

Según la teoría crítica, Hegel, después de haber percibido la contradicción entre el discurso y la realidad, deja para la filosofía la tarea de conciliar a los hombres con su presente, con su situación histórica y, con este objetivo, concibe la realización del Derecho abstracto como proceso objetivo. La filosofía de Hegel se convierte así, según la teoría crítica, en retrospectiva y conciliadora, incapaz de servir de impulso a la praxis futura. Concilia el hombre con su presente desagradable y impide, de esa manera, la transformación social que desea Marx, deseo con lo cual comparte la teoría crítica.

La crítica marxiana, como la hegeliana, denuncia las contradicciones escondidas en la sociedad capitalista y se sirve de la fuerza explosiva de la explotación en la forma capitalista de producción, pero, diferente de Hegel, Marx no camina hacia una filosofía conciliadora, retrospectiva y dialéctica, sino hacia una filosofía transformadora y revolucionaria, que busca cambiar la sociedad. Marx entiende que los hombres mismos son sujetos de su propia historia y la van construyendo aun cuando, como consecuencia del fuerte discurso ideológico del capitalismo, basado sobre el trabajo alienado, no se dan cuenta de esto. Marx creía que dicha contradicción sería superada cuando el proletariado estuviera suficientemente maduro para asumir sus tareas revolucionarias, que este día llegaría tras mucho tiempo de explotación del proletariado por parte de la burguesía y que esta sería la consecuencia natural del desarrollo desenfrenado del capitalismo.

Sus previsiones no se confirmaron y la Escuela de Frankfurt sigue con su problemática pero buscando otras soluciones. Según los frankfurtianos, 
Marx siguió, como Hegel, buscando la superación de la contradicción capitalista en un nivel general, universal y, por lo tanto, no logró ser del todo consecuente en su tarea de criticarlo. La contribución de Freud hará posible pensar una solución en una dimensión de las relaciones y interrelaciones de los hombres entre sí. Los estudios de psicoanálisis permitieron empezar las reflexiones a un nivel individual y no colectivo como hasta este momento, permitió, también, el análisis del papel de la comunicación, que será fundamental para el desarrollo de la teoría crítica y, principalmente, para la teoría de la acción comunicativa de Habermas.

La teoría crítica buscó, por lo tanto, basada en los tres teóricos citados, impulsar una praxis humana hacia una emancipación crítica de toda opresión y hacia el desenmascaramiento crítico de la presunta objetividad de los poderes. Buscó responder a los planteamientos de esta tradición pero sin caer en el objetivismo que cada uno de sus teóricos antecesores acabaran por sucumbir. En este contexto, presentamos a seguir un breve recorrido histórico de las generaciones de la Escuela de Frankfurt, sus diferencia y principales aportaciones a la teoría de la acción comunicativa habermasiana.

\section{ESCUELA DE FRANKFURT: PRIMERA GENERACIÓN}

La primera generación de la Escuela de Frankfurt ${ }^{7}$ fue marcada, principalmente, por el sufrimiento del nazismo y por la tarea, siempre presente de, en frase de Adorno: "lograr que Auschwitz no se repita". Los principales teóricos de esta generación (Horkheimer, Marcuse y Adorno) dirigen su crítica hacia una sociedad económicamente desarrollada y que, en contra las previsiones marxianas, ha agudizado todavía más su deshumanización. Son, los tres, críticos radicales de lo que más tarde se llamó la "sociedad del bienestar social" y en la cual el aparato económicoadministrativo logra hacer con que los hombres "siéntanse felices, aun cuando en realidad no lo son." ${ }^{8}$ Se trata de una fuerte alienación, lograda mediante una interiorización de las necesidades inducidas por el sistema político-económico.

Al trabajar con lo que llamó cultura industrial, Horkheimer, por ejemplo, hizo una distinción entre el concepto de razón subjetiva 
(preocupada en encontrar los fines que el hombre persigue) y razón objetiva (preocupada en resolver problemas técnicos de la relación entre medios y fines). Horkheimer denunció, entonces, la transformación de la razón objetiva en razón instrumental y el consecuente proceso de deshumanización del hombre como resultado del desarrollo del sistema económico. En este sentido, apuntó el avance del positivismo en las ciencias sociales como prueba de la consagración de esta razón instrumental. Pero, por otro lado, subrayó el hecho de la alienación ser creada y sostenida por el propio hombre y de este poder, entonces, derivar la posibilidad de su eliminación, con una praxis orientada por la teoría crítica.

Adorno desarrolla el concepto de razón identificante que, al ocuparse de los aspectos técnico-económicos del desarrollo social, eterniza y consolida el discurso vigente, y, por lo tanto, adquiere un carácter ideológico que evita el desenmascaramiento de la realidad de opresión del sistema capitalista. Adorno subraya también la ambigüedad del desarrollo técnico, que puede conducir la sociedad para un real avance social como también para su deterioración.

Marcuse, como Horkheimer y Adorno, denuncia que el propio aparato técnico-económico produce armas para defenderse de cualquier tentativa de crítica al sistema, arma que llamó razón unidimensional y que es la que permite el dominio sobre la Naturaleza y sobre los hombres y, a la vez, sirve de legitimación del propio sistema de organización social existente. Esa razón unidimensional, que actúa, principalmente, a nivel psicológico, torna impotentes a los hombres ante tamaña alienación. Así, parece evidente la influencia de la tradición teórica citada en los tres principales representantes de la primera generación de la Escuela de Frankfurt.

J. Habermas, como se dijo, es, a su vez, el principal representante de la segunda generación de la Escuela de Frankfurt, una generación que no sufrió directamente los horrores de la guerra ni del nazismo, pero que hereda las preocupaciones y la tradición crítica a la sociedad capitalista de sus antecesores. Habermas desarrolla su pensamiento en un contexto histórico y político muy distinto de la primera generación; se sitúa en la Alemania reconstruida de la posguerra, del desarrollo y posterior crisis 
de los estados de bienestar, del surgimiento de nuevas desigualdades y nuevos movimientos sociales y de muchas otras características que indican la creciente complejidad de las sociedades capitalistas occidentales contemporáneas.

A partir del trabajo realizado por la primera generación, pero buscando superarla, tras reconocer sus limitaciones, Habermas propondrá un cambio de paradigma y una nueva y revolucionaria mirada de los problemas sociales, una vez que ve, en el paradigma cartesiano, el gran problema de la primera generación, como lo apunta Mardones:

Habermas está convencido en su ultima obra que el fracaso de la primera teoría crítica no se debe a este o aquel fallo, sino al agotamiento del paradigma de la filosofía de la conciencia. La primera generación de los Adorno, Horkheimer, Marcuse, trabajaban con un modelo que procede de la filosofía moderna del sujeto. Desde Descartes, y más todavía desde Kant, se afianza una representación, que concibe al sujeto, como sujeto cognoscente en relación con aquello que yace echado delante de él, objeto. Este esquema propio de la teoría del conocimiento ha impregnado toda la filosofía moderna. ${ }^{9}$

La gran obra que marca el desarrollo del pensamiento habermasiano se titula teoría de la acción comunicativa y su publicación, en 1981, constituyó el resultado de años de trabajo con el objetivo de construir una teoría de la sociedad con intención práctica. En su obra influyeron importantes teóricos además de los ya citados, entre ellos: Weber, Mead, Luckacs, Durkheim y Parsons, teóricos que hacen, a través de sus obras, parte de un diálogo inacabado con Habermas y su teoría.

La teoría de la acción comunicativa hace un análisis de las diferentes formas de interacción humana, y destaca en ellas distintos mecanismos de coordinación de acciones, modelos de racionalidad y paradigmas filosóficos. Su objetivo principal es construir una teoría de la sociedad con intención práctica y denunciar la crisis de la razón y la perdida de capacidad del ser humano de objetivar críticamente el mundo en que vive. Así, las tres finalidades a que se propone son: 1- desarrollar un concepto de racionalidad que no esté limitado por las premisas subjetivistas y individualistas de la filosofía cartesiana; 2- desarrollar un concepto de sociedad en dos niveles, 
que integre sistema y mundo de la vida; 3 - desarrollar una teoría crítica de la modernidad que analice y encuentre las causas de sus patologías.

\section{LA NECESIDAD DE LA SUPERACIÓN DEL PARADIGMA CARTESIANO}

Habermas propone un nuevo paradigma como alternativa al vigente por considerarlo con sus posibilidades ya insuperablemente limitadas, como se puede comprobar en sus propias palabras: "El paradigma de la filosofía de la conciencia se encuentra agotado. Así, los síntomas de dicho agotamiento se deben disolver en la transición para el paradigma de la comprensión." ${ }^{10}$ Así, como apunta Mardones, "con este nuevo paradigma quiere presentar Habermas una alternativa que elimine las deficiencias y fracasos que advierte en la primera generación francofkfurtina" 11

Descartes, como un buen filósofo moderno, tenía como prioridad garantizar la autonomía del sujeto y, con este objetivo, siguió por el camino de sus "dudas metódicas"12 hacia el "Cógito, ergo sum". El sujeto cartesiano tiene, entonces, como características centrales: la independencia, la autonomía y el aislamiento, pero también, como no reconocer, una cierta arrogancia y prepotencia de un sujeto que se imagina "libre" de influencias, que se autoconstruye de manera independiente y que, armado de sí mismo, sale a comprender, desvelar y dominar el mundo.

Desde Descartes, la filosofía moderna se ha construido, pues, a partir de un principio fundamentalmente existencial y sustancial de la conciencia. Consiste en una concepción filosófica que entiende el sujeto de forma probablemente ingenua y demasiadamente independiente. Lo comprende de forma solitaria, como un sujeto que establece una relación en un único sentido con el mundo (sujeto -> objeto): el sujeto que descubre el objeto, aun cuando este objeto pueda ser otro sujeto (también pensado como independiente y solitario). Así, el sujeto cartesiano es un sujeto presuntamente independiente que desvela el mundo, que actúa sobre y en contra el otro, que subyuga, controla y domina. En este paradigma, pues, el otro es siempre un obstáculo a ser superado. Se trata, en fin, del paradigma cartesiano del "Sujeto", con la "S" mayúscula. 
Habermas hace un análisis de la trayectoria de la historia reciente de la filosofía y detecta lo que considera limitaciones insuperables del paradigma de la filosofía de la conciencia y, por este motivo, se propone a superarla. Detecta dichas limitaciones aun mismo en filosofías de colegas suyos de la Teoría Crítica frankfurtiana, como Horkheimer y Adorno. Ha sido este, exactamente, el principal motivo de su rompimiento con la llamada primera generación de la Escuela de Frankfurt Los acusa de dejar sin resolver la cuestión de la justificación de su propio discurso, una vez que dictaminan la unilateralidad de la razón instrumental. No llegan a superar los problemas de limitaciones del paradigma cartesiano, sino sólo alejarlo o postergalo. En palabras del propio Habermas: "Las categorías básicas de la Teoría Crítica enfrentan directamente la conciencia de los individuos a unos mecanismos sociales de integración que se limitarían a prolongarse hacia dentro, intrapsíquicamente". ${ }^{13}$

Será superar el paradigma cartesiano, pues, lo que contribuirá para que Habermas deje para tras el pesimismo paralizante de la primera generación de Frankfurt y pueda creer que el proyecto ilustrado no se ha completado, pero que se puede hacerlo. Tras superar el paradigma cartesiano, Habermas mantiene todavía los objetivos y las convicciones frankfurtianas, pero, no obstante, abandona la crítica derrotista y sin salida para reconstruir las potencialidades liberadoras de la razón comunicativa, pues, como dice el propio Habermas, "Mi opinión es que, en vez de dar por perdido lo moderno y su proyecto, debemos más bien aprender de sus equivocaciones y de los errores de su exagerado proyecto de superación". ${ }^{14}$

\section{EL PARADIGMA HABERMASIANO}

Para superar las debilidades teóricas que denuncia en sus predecesores, Habermas cree en el potencial de su teoría de la acción comunicativa, en la que el sujeto nunca está hecho y listo para salir a desvelar y dominar el mundo, como lo hacía el sujeto cartesiano, sino que se construye y reconstruye constantemente en la interacción con los demás sujetos. El otro deja de ser entendido como un obstáculo a ser superado y pasa a ser entendido como un interlocutor que negocia con el otro sujeto y, juntos, construyen el consenso y el entendimiento. Construyen el discurso 
siempre falible y sujeto a amplias y seguidas revisiones. Se trata, en fin, del paradigma habermasiano de la "intersubjetividad". La postura e interés habermasianos quedan claros en esta cita:

Sugerí que el paradigma del conocimiento de objetos tiene que ser sustituido por el paradigma de la comprensión mutua entre los sujetos capaces de hablar y actuar. Hegel y Marx no cumplieron dicho cambio de paradigma; Heidegger y Derrida, al intentaren dejar para tras la metafísica de la subjetividad, quedaron presos a la intención de la filosofía de origen. También Foucault a partir del momento en que analizó la obligatoriedad de una duplicación aporética del sujeto auto-referente, derivó para una teoría del poder que se ha revelado como una vía sin salida. ${ }^{15}$

Así, si pasamos de un sujeto aislado e independiente (al menos supuesto como tal), a un sujeto que interactúa y negocia, parece clara la importancia que el lenguaje asume en el paradigma habermasiano, una vez que:

En sus operaciones interpretativas los miembros de una comunidad de comunicación deslindan el mundo objetivo y el mundo social que intersubjetivamente comparten, frente a los mundos subjetivos de cada uno y frente a otros colectivos. Los conceptos de mundo y las correspondientes pretensiones de validez constituyen el armazón formal de que los agentes se sirven en su acción comunicativa para afrontar en su mundo de vida las situaciones que en cada caso se han tornado problemáticas, es decir, aquellas sobre las que se hace menester llegar a un acuerdo. ${ }^{16}$

Dichas operaciones e interacciones sólo se hacen posible "en" y "a través” del lenguaje, porque para la construcción del consenso y la búsqueda por el entendimiento, la comunicación ejerce, pues, papel central.

En este contexto, el concepto de conocimiento, en la concepción tradicional cartesiana, que se centra en el sujeto y se resume en "desvelar" el mundo, en comprender la realidad exterior, permitiría la existencia (o seudo-existencia) de "conciencias iluminadas y superiores" que detectan la "verdadera esencia de la realidad". De esta concepción deriva la dificultad de la existencia de una postura crítica y creativa por parte de los individuos, una vez que el aprendizaje se asentaría, pues, en el presupuesto de la existencia de "una" verdad. En este contexto, a la escuela, por ejemplo, restaría sólo 
el papel de reproductor y transmisor del conocimiento "acabado" (o al menos que se cree serlo).

En la óptica habermasiana, al contrario, el conocimiento es comprendido como una realización intersubjetiva y como fenómeno social, donde el conocimiento es centrado y construido en la intersubjetividad. En el nuevo paradigma, no ocurre, pues, el "desvelamiento" del mundo, sino al revés, se acentúa el carácter histórico de la información. El conocimiento no es trasmitido, sino resultado de un proceso de construcción y que, así, asume carácter provisional. La escuela, en este contexto, pasa a tener el papel de posibilitar la problematización y la apropiación crítica de los saberes, constituiría suelo fértil para el fortalecimiento de la Acción Comunicativa.

En el paradigma cartesiano, la importancia y la comprensión del papel del lenguaje se restringe a su uso proposicional, o sea, como un instrumento que permite al hablante informar al oyente sobre algo en el mundo (personas, cosas, hechos) y verbalizar el contenido de un enunciado a través de la expresión del uso cognitivo del lenguaje, pero sin vislumbrar o enfatizar la posibilidad de una relación intersubjetiva entre los hablantes. El lenguaje es sólo un medio para lograr determinado objetivo: transmitir una información o un orden y la relación establecida con el otro es fundamentalmente sobre el mundo. Se trata de situaciones en las que el otro es un receptor de la información y no un agente que efectivamente se relaciona con el hablante. ${ }^{17}$

El paradigma habermasiano, a su vez, rescata el uso preformativo del lenguaje, o sea, cuando la comunicación no es entendida como sólo transmisión de información y entendimiento sobre las cosas en el mundo, sino como el medio que posibilita la producción de un nexo intersubjetivo de interacción entre los participantes de la comunicación. En el uso efectivamente comunicativo del lenguaje (acto de habla) está siempre presente, pues, una tríplice relación: la intención del hablante consigo mismo (mundo subjetivo), la relación interpersonal del hablante con el oyente (mundo social) y la expresión de algo sobre el mundo (mundo objetivo).

De ahí se sigue que un acto de habla sólo puede ser comprendido y hacer sentido dentro de su propio contexto, a partir del telón de hondo de los saberes compartidos que constituyen su mundo de la vida. "Al actuar 
comunicativamente los sujetos se entienden siempre en el horizonte de un mundo de vida. Su mundo de vida está formado de convicciones de fondo, más o menos difusas, pero siempre aproblemáticas. El mundo de vida, en tanto que trasfondo, es la fuente de donde se obtienen las definiciones de la situación que los implicados presuponen como aproblemáticas". ${ }^{18}$

Es importante subrayar que en una acción comunicativa las pretensiones de validez son siempre criticables, una vez que el entendimiento es comprendido como "proceso" y jamás como una posición definida y definitiva. Así, está claro que para que exista siempre abierta la posibilidad del diálogo, es necesario que haya siempre la posibilidad de dudar del enunciado. Verdades incuestionables congelarían el diálogo y, por lo tanto, impedirían la posibilidad de una acción efectivamente comunicativa.

\section{Conclusiones: El optimismo del paradigma de la intersubjetividad}

Está claro que la teoría de la acción comunicativa constituye una manera reflexiva y eficaz de observar el proceso de construcción social, de apuntar y comprender los hábitos y las estructuras sociales. Es una forma de describir críticamente la razón funcionalista de la modernidad y de iniciar un proceso de crítica social en la búsqueda de la emancipación y del esclarecimiento. Especialmente al constituirse como un nuevo paradigma, una nueva perspectiva de concebir el sujeto y sus relaciones con los otros sujetos y con el mundo. Un paradigma intersubjetivo, en el que el lenguaje, a través de sus actos de hablas y competencias comunicativas, asume papel tan importante y fundamental exactamente por constituirse como instrumento que permite el encuentro, el cambio y, en fin, el reconocimiento y la inclusión del otro. Así, asumiendo lo mismo que apunta Mardones, afirmamos que:

Habermas cree que el modelo de la racionalidad comunicativa puede mantener las intenciones que animaron y guiaron a la primera Teoría Crítica: el análisis crítico, interdisciplinar de la sociedad; la construcción de una ciencia de la sociedad capaz de proporcionar el diagnóstico adecuado para la cura de las patologías sociales; la vinculación entre el ser y el deber ser o de la razón teórica y la razón práctica, a fin de conseguir una teoría de la sociedad que junte a la fuerza de la verdad de los datos, la de la rectitud de 
los principios; la formulación de una teoría de la racionalidad no recortada, que permita entender el desarrollo humano y preparar el próximo futuro de mayor libertad y justicia. ${ }^{19}$

Así, partir del breve histórico de sus orígenes trazado y de la presentación de su principal contribución, proponemos la fecundidad y el protagonismo de la teoría de la acción comunicativa de Habermas e invitamos, huyendo de cualquier prejuicio teórico, a utilizarla como fundamento para futuras reflexiones respecto los problemas y conflictos de nuestro tiempo por cuatro razones esenciales: 1- por la posibilidad de tomarla como un profundo y cuidadoso análisis diagnóstico de los problemas contemporáneos de la sociedad occidental; 2- por creer encontrar en ella suficiente instrumental teórico para discutir dichos problemas, en virtud de su empeño en no detenerse en el momento negativo de la crítica sino de contribuir a la construcción de un proyecto social alternativo; 3 - por ver en ella la propuesta de una nueva manera de ver el mundo, a partir de un paradigma mucho más incluyente y justo que el paradigma cartesiano, especialmente en un mundo excluyente, pragmático y patriarcal como el que todavía vivimos; 4- principalmente, por vislumbrar en ella rasgos de un optimismo tan raro como necesario en el horizonte intelectual actual.

\section{COMENTARIOS Y REFERENCIAS}

1. Es importante aquí aclarar que respecto a dicha crisis de la ciencia, Gómez-Heras subraya, sin embargo, no ser una crisis de cientificidad, sino de sentido. "El lugar de la crisis es aquel proyecto de vida que sirve de referencia para pronunciarse sobre el sentido y significado del saber y de la técnica para la existencia humana. Es decir: el lugar de la crisis es el mundo ético-político”. p. 34 In: GÓMEZ-HERAS, José M. G. El apriori del mundo de la vida. Fundamentación fenomenológica de una ética de la ciencia y de la técnica. Barcelona: Anthropos, 1989

2. GÓMEZ-HERAS, José M. G. El apriori del mundo de la vida. Fundamentación fenomenológica de una ética de la ciencia y de la técnica. Barcelona: Anthropos., 1989 p. 36

3. HABERMAS, Jürgen. Consciência moral e agir comunicativo. Rio de Janeiro: Tempo Brasileiro, 1989 , p. 25

4. HABERMAS, Jürgen. (1989) Idem, p. 25

5. UNZUETA ALBERDI, Iñaki. La crisis de la sociedad del trabajo - De Marx a la Escuela de Francfort, Bilbao: Universidad del País Vasco, 2000, p. 185

6. MARDONES, José María «La reconstrucción de la Teoría Crítica por J. Habermas. A propósito de Theorie dês Kommunikativen Handelns», Pensamiento Vol. 40 pp. 159-177, 1984, p. 177

7. Sobre la primera generación de la Escuela de Francfort se sugiere el útil y completo resumen de la III parte del libro: UNZUETA ALBERDI, Iñaki. La crisis de la sociedad del trabajo - De Marx a la 
Escuela de Francfort, Bilbao: Universidad Del País Vasco, 2000

8. NOGUERA, J. A. «La teoría crítica: de Frankfurt a Habermas. Una tradución de la teoría de la acción comunicativa a la sociología», Papers, 50, 1996, pp. 133-153, p. 137

9. MARDONES, José María «La reconstrucción de la Teoría Crítica por J. Habermas. A propósito de Theorie dês Kommunikativen Handelns», Pensamiento Vol. 40 pp. 159-177, 1984, p. 163

10.HABERMAS, J. O Discurso filosófico da modernidade. Lisboa: Publicações Dom Quixote, 1990, p. 277

11.MARDONES, José María «La reconstrucción de la Teoría Crítica por J. Habermas. A propósito de Theorie dês Kommunikativen Handelns», Pensamiento Vol. 40 pp. 159-177, 1984, p. 167

12.DESCARTES, René. Discurso del método. Madrid: Tecnos, 1987

13.HABERMAS, Jürgen. Consciência moral e agir comunicativo. Rio de Janeiro: Tempo Brasileiro, 1989 , p. 540

14.HABERMAS, J. Ensayos políticos. Barcelona: Península, 1988, p. 279

15.HABERMAS, J.O Discurso filosófico da modernidade. Lisboa: Publicações Dom Quixote, 1990, p. 276

16.HABERMAS, Jürgen. Consciência moral e agir comunicativo. Rio de Janeiro: Tempo Brasileiro, 1989, p. 176

17.HABERMAS, Jürgen. Consciência moral e agir comunicativo. Rio de Janeiro: Tempo Brasileiro, 1989 , p. 341

18.HABERMAS, Jürgen. Consciência moral e agir comunicativo. Rio de Janeiro: Tempo Brasileiro, 1989, p. 541

19.MARDONES, José María «La reconstrucción de la Teoría Crítica por J. Habermas. A propósito de Theorie dês Kommunikativen Handelns», Pensamiento Vol. 40 pp. 159-177, 1984, p. 167 